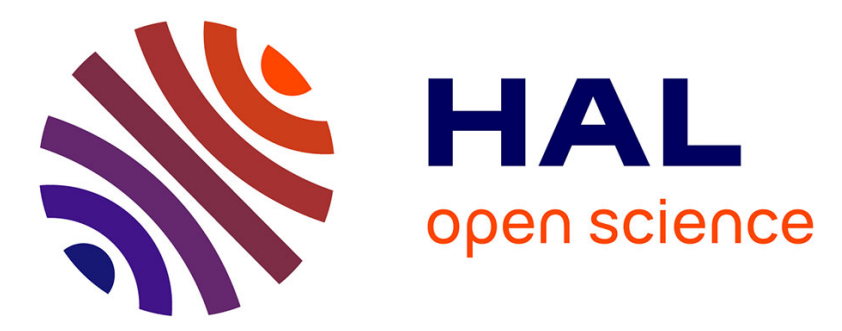

\title{
OPTICAL, ELECTRICAL AND MAGNETIC PROPERTIES OF CHALCOPYRITE, CuFeS2
}

T. Teranishi, K. Sato

\section{To cite this version:}

T. Teranishi, K. Sato. OPTICAL, ELECTRICAL AND MAGNETIC PROPERTIES OF CHALCOPYRITE, CuFeS2. Journal de Physique Colloques, 1975, 36 (C3), pp.C3-149-C3-153. 10.1051/jphyscol:1975327 . jpa-00216297

\section{HAL Id: jpa-00216297 https://hal.science/jpa-00216297}

Submitted on 1 Jan 1975

HAL is a multi-disciplinary open access archive for the deposit and dissemination of scientific research documents, whether they are published or not. The documents may come from teaching and research institutions in France or abroad, or from public or private research centers.
L'archive ouverte pluridisciplinaire HAL, est destinée au dépôt et à la diffusion de documents scientifiques de niveau recherche, publiés ou non, émanant des établissements d'enseignement et de recherche français ou étrangers, des laboratoires publics ou privés. 


\title{
OPTICAL, ELECTRICAL AND MAGNETIC PROPERTIES OF CHALCOPYRITE, $\mathrm{CuFeS}_{2}$
}

\author{
T. TERANISHI and K. SATO \\ Broadcasting Science Research Laboratories of Nippon Hoso Kyokai \\ Setagaya, Tokyo 157, Japan
}

\begin{abstract}
Résumé. - Diverses propriétés optiques, électriques et magnétiques du semiconducteur magnétique $\mathrm{CuFeS}_{2}$ ont été étudiées. Les spectres optiques montrent que le bord d'absorption se situe à $0,6 \mathrm{eV}$ pour $\mathrm{CuFeS}_{2}$ alors que de fortes bandes d'absorption apparaissent à 1,3 et 2,0 eV pour $\mathrm{CuAIS}_{2}$ dopé au Fe. La photoconductivité a été observée dans la même région spectrale. Ces fortes absorptions ont pour origine des transitions de transfert de charge en relation avec les orbitales $3 \mathrm{~d}$ du Fe, et le bord d'absorption de $\mathrm{CuFeS}_{2}$ résulte de transitions bande à bande correspondant à ces transitions de transfert de charge. Pour $\mathrm{CuFeS}_{2}$ de types n et $\mathrm{p}$, la conductivité électrique augmente légèrement quand la température décroît et la concentration des porteurs est indépendante de la temperature. Les valeurs des mobilités sont faibles : $10 \mathrm{~cm}^{2} / \mathrm{V}$.s pour le type n et $1 \mathrm{~cm}^{2} / \mathrm{V}$.s pour le type $\mathrm{p}$. La susceptibilité magnétique est indépendante de la température entre 40 et $600 \mathrm{~K}$ et elle est d'environ $10^{-3}$ par mole.

Ce comportement métallique apparent des propriétés électriques et magnétiques se comprend à partir d'un modèle de semiconducteur dégénéré où les orbitales $3 \mathrm{~d}$ fortement hybridées aux orbitales $s$ et $p$ constituent les bandes de valence et de conduction.
\end{abstract}

Abstract. - Various optical, electrical and magnetic properties of a magnetic semiconductor, $\mathrm{CuFeS}_{2}$, have been studied. Optical absorption spectra show the absorption edge at $0.6 \mathrm{eV}$ for $\mathrm{CuFeS}_{2}$ and strong absorption bands at $1.3 \mathrm{eV}$ and $2.0 \mathrm{eV}$ for Fe-doped CuAlS 2 . Photoconductivity is also observed at the same energy region of the absorption edge. These strong absorptions originate from the charge transfer transitions relating to $3 \mathrm{~d}$ orbitals of $\mathrm{Fe}$ and the absorption edge of $\mathrm{CuFeS}_{2}$ rises from the band-to-band transition corresponding to this charge transfer transition. For $\mathrm{n}$ - and $\mathrm{p}$-type $\mathrm{CuFeS}_{2}$ electrical conductivities increase slightly with decreasing temperature and carrier concentrations do not depend on temperature. Mobility has small value as $10 \mathrm{~cm}^{2} / \mathrm{V}$.s for n-type specimen and $1 \mathrm{~cm}^{2} / \mathrm{V}$. $\mathrm{s}$ for p-type. Magnetic susceptibility is also temperature independent between $40 \mathrm{~K}$ and $600 \mathrm{~K}$ and its magnitude is $10^{-3}$ per mol.

These apparent metallic behaviors of electric and magnetic properties are understood from a model of a degenerate semiconductor where $3 \mathrm{~d}$ orbitals are appreciably admixed with $\mathrm{s}$ and $\mathrm{p}$ orbitals and compose both the conduction and valence band.

1. Introduction. - Chalcopyrite, $\mathrm{CuFeS}_{2}$, is the only one magnetic semiconductor among the chalcopyrite type ternary semiconducting compounds. Electrical [1,2], magnetic $[3,2]$, and optical $[4,5]$ properties of chalcopyrite have been examined by some investigators. The results of these investigations have been interpreted from a standpoint of an ordinary non magnetic semiconductor or a simple magnetic material. But some experimental results, for instance, the low mobility of n-type chalcopyrite [2], the small value of effective magnetic moment obtained by neutron diffraction experiment [3], the extraordinarily high Néel temperature [2] and the low optical absorption edge $[4,5]$ are not understood from a model of a simple semiconductor or a magnetic material. It is possible to interpret these anomalous values by a conception of the magnetic semiconductor.

Recently we have observed the optical absorption of $\mathrm{CuFeS}_{2}$, and Fe-doped $\mathrm{CuAlS}_{2}$ and $\mathrm{CuGaS}_{2}$ [6]. It has been clarified that the transition from the valence band to the $3 \mathrm{~d}$ states causes the strong absorption. Theoretical calculations based on the molecular orbital method have revealed the nature of this transition quantitatively [7].

Still most of the above mentioned difficulties have remained abstruse.

The present work was undertaken to study the role of $3 \mathrm{~d}$ orbitals in optical, electrical and magnetic properties, and to find a clue to solve the above mentioned difficulties.

We were able to make p-type specimens of chalcopyrite as well as n-type ones. In the present paper are described the results of electrical and magnetic measurements on specimens of both types, including the optical data published by us before [6].

2. Experimental. - 2.1. - A thin evaporated film of $\mathrm{CuFeS}_{2}$ was used for the optical measurement. As for Fe-doped CuAlS 2 and $\mathrm{CuGaS}_{2}$ we used single crystals which were grown as blades by the chemical 
transport reaction. The details of the growing procedures of the film and crystals were described in a previous paper [6].

For the electrical measurement a bulky single crystal of $\mathrm{CuFeS}_{2}$ was grown by the direct melting method. Powder of $\mathrm{CuFeS}_{2}$ was put in the silica crucible, the tip of which was sharply pointed, and the crucible was suspended in the growing furnace. The temperature of the furnace was lowered at a rate of $2{ }^{\circ} \mathrm{C} /$ hour or the crucible was lowered at a rate of $20 \mathrm{~mm} /$ day. This lowering rate was similar to that used by Adams et al. [8].

Because the most probable ionic state of chalcopyrite is $\mathrm{Cu}^{+} \mathrm{Fe}^{3+} \mathrm{S}_{2}^{2-}$ it is possible to make a p-type specimen by reducing the valency of cations or by increasing the valency of anions. We have succeeded in preparing a p-type specimen of chalcopyrite by three ways : 1) the substitution of $\mathrm{Zn}^{2+}$ ions for $\mathrm{Fe}^{3+}$, $\left.\mathrm{CuFe}_{1-x} \mathrm{Zn}_{x} \mathrm{~S}_{2}, 2\right)$ the substitution of $\mathrm{Cu}^{1+}$ ions for $\left.\mathrm{Fe}^{3+}, \mathrm{Cu}_{1+x} \mathrm{Fe}_{1-x} \mathrm{~S}_{2}, 3\right)$ the substitution of $\mathrm{Sb}^{3-}$ ions for $\mathrm{S}^{2-}, \mathrm{CuFeS}_{2-x} \mathrm{Sb}_{x}$. Sintered polycrystalline specimens of all these p-type compounds were prepared by the direct combination of elements.

An attempt to make a p-type single crystal by the chemical transport reaction was successful only for the series of $\mathrm{CuFe}_{1-x} \mathrm{Zn}_{x} \mathrm{~S}_{2}$. All single crystals grown by direct melting of these substituted powder specimens were not of p-type but n-type. Because a smail amount of yellow elemental sulfur was sometimes noticed on the surface of the crystal boule, it is supposed that the cause of forming the n-type crystals is the deficiency of sulfur in the crystal.

All samples were analysed by $x$-ray diffraction techniques and ascertained that phases other than chalcopyrite were not present.

2.2 Optical measurements. - Optical absorption measurements were made with a Cary 14 spectrophotometer. In the range of wave length beyond $2 \mu \mathrm{m}$ a single beam infrared spectrometer was used.

2.3 Electrical measurements. - The electrical conductivity and the Hall effect were measured by five electrode method. The contact of electrodes to the specimen was made with an In amalgam.

For p-type specimens except one which was introduced by $\mathrm{Zn}^{2+}$ ions the measurement was made on sintered polycrystalline samples at room temperature.

2.4 Magnetic mensurements. - Magnetic susceptibility data were obtained using a Faraday balance. The correction for diamagnetism was performed on the basis of molar diamagnetic susceptibilities given by Selwood [9].

3. Results and Discussion. - 3.1 OPTICAL ABSORPTION. - The evaporated thin film of $\mathrm{CuFeS}_{2}$ shows a strong absorption rising at $0.6 \mathrm{eV}$ as shown in figure 1 (curve a). This is regarded as the absorption edge of chalcopyrite by Austin et al [5]. The Fe-doped

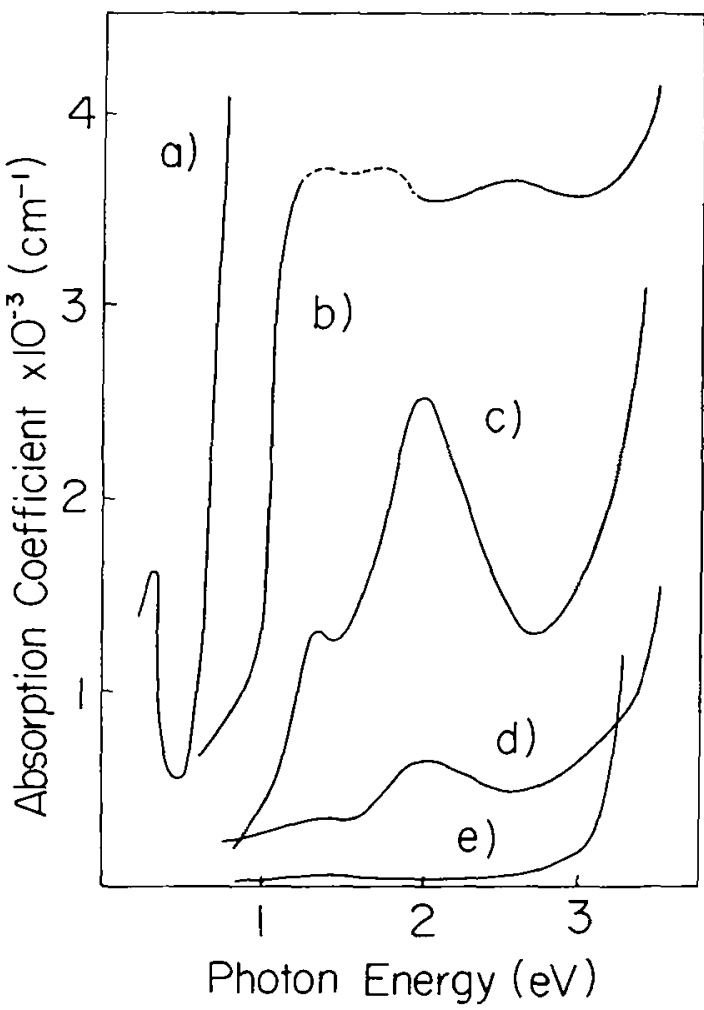

FIG. 1 -Absorption spectra of $a$ ) $\left.\mathrm{CuFeS}_{2}, b\right) \mathrm{CuAl}_{0.93} \mathrm{Fe}_{0.07} \mathrm{~S}_{2}$, c) $\left.\mathrm{CuAl}_{0.994} \mathrm{Fe}_{0.006} \mathrm{~S}_{2}, d\right) \mathrm{CuAl}_{0.9992} \mathrm{Fe}_{0.0008} \mathrm{~S}_{2}$, and $e$ ) $\mathrm{CuAlS}_{2}$.

$\mathrm{CuAlS}_{2}$ crystals show the strong absorption band at $1.3 \mathrm{eV}$ and $2.0 \mathrm{eV}$ besides the fundamental absorption edge rising at $3.3 \mathrm{eV}$ (Fig. 1, curve b, c and d). The intensity of these absorption increases with the amount of doped $\mathrm{Fe}$ ions and grows into the absorption edge of $\mathrm{CuFeS}_{2}$. The similar results are obtained for $\mathrm{CuGaS}_{2}$ : Fe [6].

It is naturally expected that $3 \mathrm{~d}$ electrons take part in this absorption. Since the estimated oscillator strength is as large as $7 \times 10^{-2}$, it is indicated that this large absorption does not result from a typical $d-d$ transition of isolated magnetic ions but from a charge transfer transition between the valence band and the empty $3 \mathrm{~d}$ states. Moreover, at liquid nitrogen temperature the photoconductivity is observed on a natural single crystal of $\mathrm{CuFeS}_{2}$ just at the energy region where the absorption edge is also located (Fig. 2). It is, therefore, concluded that the empty $3 \mathrm{~d}$ states form the conduction band mixed by $s$ and $p$ orbitals of sulfur and the above mentioned charge transfer transition can be regarded as a band-to-band transition.

Shay et al. have reported that the highest valence band of I-III- $\mathrm{VI}_{2}$ compounds results from a hybridization of the $\mathrm{Cu} 3 \mathrm{~d}$ orbitals with $\mathrm{p}$ orbitals on the other atoms [10]. As for $\mathrm{CuFeS}_{2}$ the filled Fe 3d orbitals as well as $\mathrm{Cu} 3 \mathrm{~d}$ ones are expected to contribute appreciably to the highest valence band.

Consequently it is believed that both conduction and valence band of $\mathrm{CuFeS}_{2}$ are indeed narrow, because they are derived from the hybridized states 


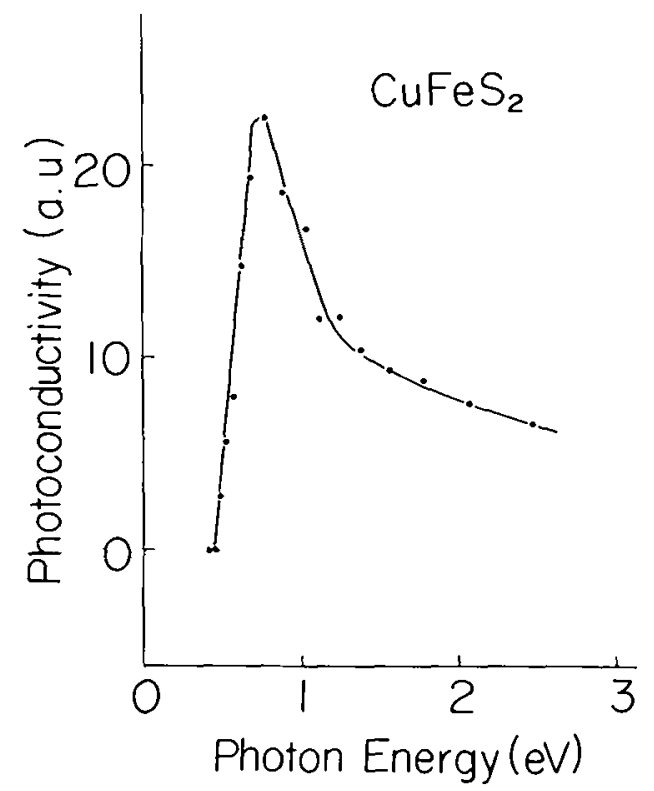

FIG. 2. - Photoconductivity spectrum of $\mathrm{CuFeS}_{2}$ at liquid nitrogen temperature.

of the d orbitals with $p$ and s orbitals. This will be supported by observing the mobility of electrons and holes.

Another evidence of the strong hybridization of $3 \mathrm{~d}$ orbitals with $\mathrm{s}$ and $\mathrm{p}$ orbitals is the low energy of luminescence lines of $\mathrm{Fe}^{3+}$. We have observed a sharp luminescence line at $0.72 \mathrm{eV}$ for $\mathrm{CuAlS}$ : $\mathrm{Fe}$ and at $0.61 \mathrm{eV}$ for $\mathrm{CuGaS}_{2}: \mathrm{Fe}$ [11]. Though the nature of transition is clarified from the observation of Zeeman effect, the pretty low energy of these emission lines is not explained in terms of the usual $\mathrm{d}$-d transition. It is theoretically explained on the basis of the $3 \mathrm{~d}$ states hybridized with $\mathrm{s}$ and $\mathrm{p}$ orbitals by taking account of configuration interaction [12].

3. 2 Electrical conductivity and Hall efFECT. Electrical measurements were carried out on two samples: a) n-type single crystal which was grown by the direct melting method and $b$ ) p-type single crystal which contained 0.1 atomic \% of $\mathrm{Zn}$ ions in nominal concentration and was made by the chemical transport method. Figure 3 shows plots of conductivity vs. temperature from room temperature to liquid nitrogen temperature. In this temperature range conductivities of both $\mathrm{n}$ - and p-type crystals decrease with the rising temperature.

Hall effect is also measured in the same temperature range and the sign of carriers is the same with that determined from the thermoelectric power. In figure 4 we show the temperature variation of carrier concentration estimated from the Hall coefficient on the basis of the simple one band model. Carrier concentrations are rather large for both crystals and have no temperature dependence.

Hall mobilities estimated from the same simple model are given in figure 5 . The mobility of the n-type

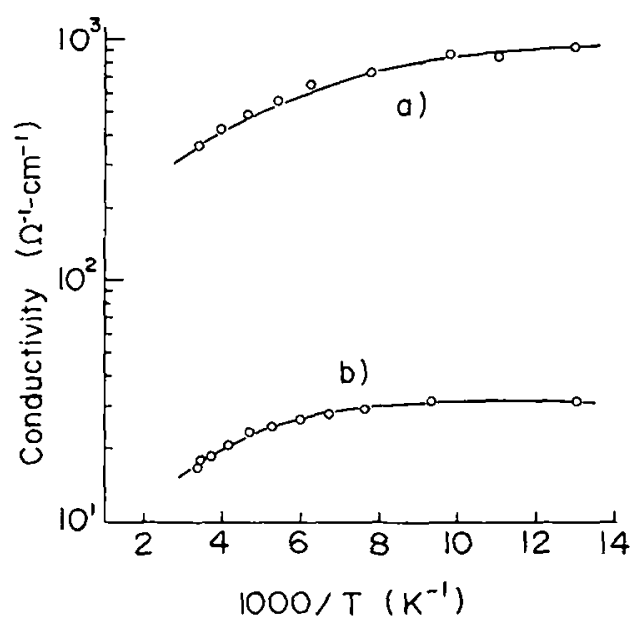

FIG. 3. - Temperature dependence of conductivity in $a$ ) n-type $\mathrm{CuFeS}_{2}$, and $b$ ) p-type $\mathrm{CuFe}_{0.9} \mathrm{Zn}_{0.1} \mathrm{~S}_{2}$.

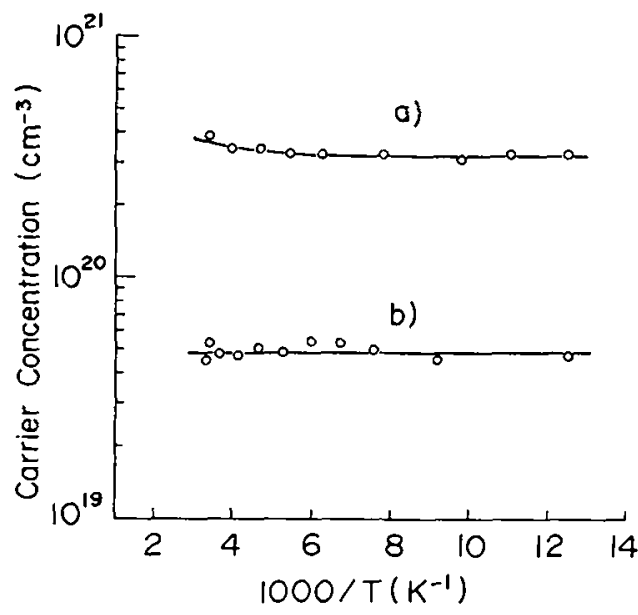

FIG. 4. - Tempcrature dependence of carrier concentration in a) n-type $\mathrm{CuFeS}_{2}$, b) p-type $\mathrm{CuFe}_{0.9} \mathrm{Zn}_{0.1} \mathrm{~S}_{2}$.

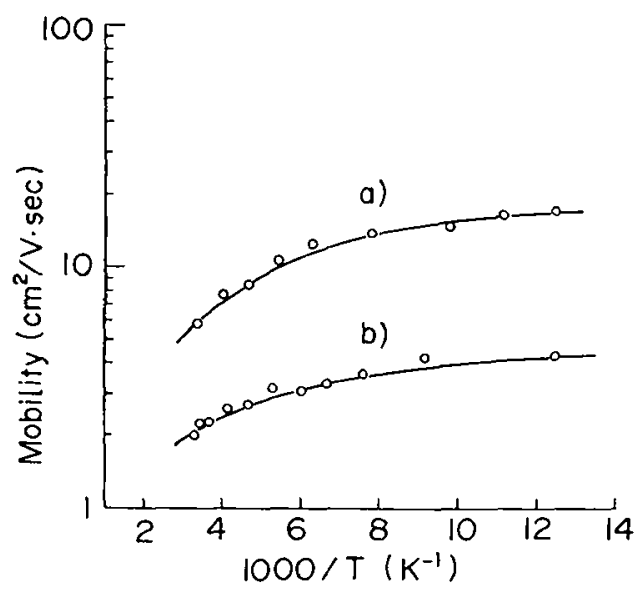

FIG. 5. - Temperature dependence of mobility in a) n-type $\mathrm{CuFeS}_{2}$ and $b$ ) p-type $\mathrm{CuFe}_{0.9} \mathrm{Zn}_{0.1} \mathrm{~S}_{2}$.

synthetic single crystal is $10 \mathrm{~cm}^{2} / \mathrm{V}$.s, being the same order of magnitude with that of a natural n-type single crystal [2]. The mobility of p-type crystal is an 
order of magnitude less than that of the n-type crystal.

Electrical properties are also measured on p-type sintered polycrystalline specimens at room temperature alone. The results are summarized in table $\mathrm{I}$. The magnitude of mobility of these p-type specimens is the same order or a little smaller than that of a single crystal.

It should be noticed here that the mobility of chalcopyrite is pretty small for both $n$ - and p-type crystals compared with an usual semiconductor which contains no magnetic ions. This indicates that the state density is large at the bottom of the conduction band and at the top of the valence band because these bands are composed of $3 \mathrm{~d}$ orbitals hybridized with $\mathrm{s}$ and $\mathrm{p}$ orbitals.

The temperature dependence of the conductivity and the temperature independent carrier concentration give evidence that this material have a metallic behavior rather than semiconducting. This is also supported by the result of magnetic susceptibility measurement as seen in a later section.

It seems natural to interpret that this metallic behavior results from the degenerate semiconducting state of chalcopyrite at room temperature. Under this condition we have attempted to obtain an estimate of the effective mass, $m^{*}$, of the carrier using [13] :

$$
T_{\mathrm{d}}=(3 \mathrm{n} / \pi)^{2 / 3}\left(\mathrm{~h}^{2} / 8 \mathrm{~km} *\right),
$$

where $T_{\mathrm{d}}$ is the degenerate temperature, $n$ is the carrier concentration. For $T_{\mathrm{d}}$ we have used the room temperature, $300 \mathrm{~K}$, and for $n$ we have used $3.5 \times 10^{20} / \mathrm{cm}^{3}$ for n-type $\mathrm{CuFeS}_{2}$ single crystal. The rate of the effective mass to the free electron mass determined in this way is 4.2. This large value is not unnatural when the small mobility of this material is taken into account.

3.3 Magnetic susceptibility. - The temperature dependence of the magnetic susceptibility is shown in figure 6 for three specimens : a) n-type natural crystal, b) n-type synthetic crystal, and $c$ ) p-type $\mathrm{Cu}_{1.1} \mathrm{Fe}_{0.9} \mathrm{~S}_{2}$.

It is remarkable that the magnetic susceptibilities of all specimens do not depend on temperature in the range between $40 \mathrm{~K}$ and $600 \mathrm{~K}$ and its amount, $10^{-3}$ per mol, is rather large. DiGiuseppe et al. have also found the temperature independent susceptibility of chalcopyrite [14], but they do not refer to its origin. The sudden increase of the susceptibility below $40 \mathrm{~K}$

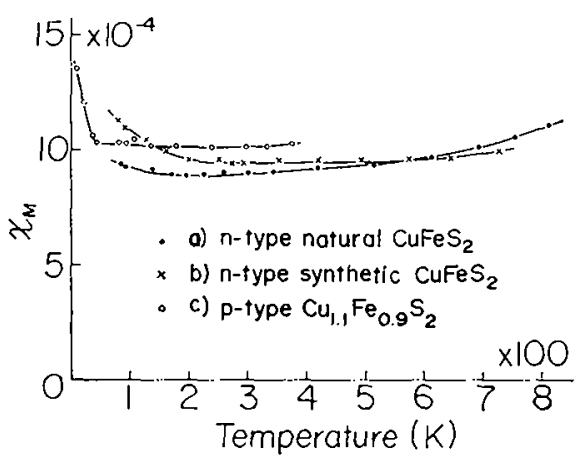

Fig. 6. - Temperature dependence of magnetic susceptibility of natural $\mathrm{CuFeS}_{2}$, synthetic $\mathrm{CuFeS}_{2}$, and $\mathrm{Cu}_{1.1} \mathrm{Fe}_{0.9} \mathrm{~S}_{2}$.

for $\mathrm{Cu}_{1.1} \mathrm{Fe}_{0.9} \mathrm{~S}_{2}$ and the slight temperature dependence in a low temperature range for the synthetic crystal may be the result of a small amount of the paramagnetic impurity, e. g. FeS, which is formed during the synthetic processes. The increasing of the susceptibility above $600 \mathrm{~K}$ is probably owing to the decomposition of specimens.

Eventually it is evident that the temperature independence of the magnetic susceptibility is the specific property of chalcopyrite ; it indicates that the susceptibility does not follow the Curie-Weiss law and electrons participating in the magnetism are more or less delocalized. As the origin of this constant susceptibility we assume the Pauli spin paramagnetism although some experimental results are unfavorable for the model: the neutron diffraction experiment shows that chalcopyrite is antiferromagnetic, and the rectifying property [1] and the large thermoelectric power [2] show chalcopyrite is not metallic but semiconducting. On the other hand the magnetic moment, $3.85 \mu_{\mathrm{B}}$, observed by a neutron diffraction is far less than $5 \mu_{\mathrm{B}}$ to be expected for localized trivalent irons [3]. Moreover, the results of Hall effect suggest the pand n-type chalcopyrite are degenerate semiconductors as shown in a previous section. These facts imply the delocalization of $d$ electrons and the apparent metallic behavior, supporting the application of the Pauli spin paramagnetism.

The theoretical calculation of the electronic structure has been carried out in the framework of the molecular orbital method and has led to the conclusion that the unoccupied $3 \mathrm{~d}$ orbitals are delocalized making the

TABLE I

Conductivity, carrier concentration and mobility of $\mathrm{p}$-type polycrystalline specimens at room temperature

$\begin{array}{lccc}\text { Substance } & \begin{array}{c}\text { Conductivity } \\ \left(\text { ohm }^{-1} \mathrm{~cm}^{-1}\right)\end{array} & \begin{array}{c}\text { Carrier concentration } \\ \left(\mathrm{cm}^{-3}\right)\end{array} & \begin{array}{c}\text { Mobility } \\ \left(\mathrm{cm}^{2} / \mathrm{V} . \mathrm{s}\right)\end{array} \\ \mathrm{CuFe}_{0.95} \mathrm{Zn}_{0.05} \mathrm{~S}_{2} & - & - & 0.5 \\ \mathrm{CuFe}_{0.9} \mathrm{Zn}_{0.1} \mathrm{~S}_{2} & 3.5 & 4.5 \times 10^{19} & 1.4 \\ \mathrm{Cu}_{1.05} \mathrm{Fe}_{0.95} \mathrm{~S}_{2} & 0.4 & 0.2 \times 10^{19} & 1.3 \\ \mathrm{CuFeS}_{1.9} \mathrm{Sb}_{0.1} & 3.9 & 1.8 \times 10^{19} & 0.3\end{array}$


conduction band while the occupied states are localized in the valence band [7].

At present it is impossible to identify where the Fermi level lies. But the large and temperature independent susceptibility results when the Fermi level situates' at the bottom of the conduction band or at the top of the valence band, both of which are composed of $3 \mathrm{~d}$ orbitals admixed with $\mathrm{s}$ and $\mathrm{p}$ orbitals. On the basis of the model of Pauli spin paramagnetism the molar susceptibility $\chi_{M}$ is given by [15]:

$$
\chi_{\mathrm{M}}=2 \mu_{\mathrm{B}}^{2} N\left(E_{\mathrm{f}}\right) \cdot N_{\mathrm{A}} \cdot 6.242 \times 10^{11},
$$

where $N\left(E_{\xi}\right)$ is the state density per magnetic ion per $\mathrm{eV}$ at the Fermi energy, $E_{\mathrm{f}}$, and $\mu_{\mathrm{B}}$ is Bohr magneton, and $N_{\mathrm{A}}$ is Avogadro number. Using the observed molar susceptibility $\chi_{\mathrm{M}}=10^{-3}$ we estimate the state density $N\left(E_{\mathrm{f}}\right)$ at $16 /$ ion. $\mathrm{eV}$. This value is reasonable, considering the similar value, $15 / \mathrm{ion} . \mathrm{eV}$, obtained from the temperature independent part of the magnetic susceptibility of $\mathrm{V}_{2} \mathrm{O}_{3}$ [16], in which the relevant energy band is composed of $3 \mathrm{~d}$ orbitals.

4. Conclusion. - From a standpoint of a magnetic semiconductor we have studied properties of $\mathrm{CuFeS}_{2}$, extending and improving the measurements of optical, electrical and magnetic properties. Though many of the studies have been hampered by poorly characterized specimens most of anomalous properties pointed out at section 1 are understood on the basis of delocalized 3d orbitals which admix appreciably with $s$ and $p$ orbitals and compose both the conduction and valence band.

But the interpretation of the temperature independent susceptibility as due to the Pauli spin paramagnetism is still rather speculative, because a degenerate semiconductor is essentially an extrinsic semiconductor. Moreover it remains unexplained whether the cocxisting of an antiferromagnetism and a metallic state is possible for $\mathrm{CuFeS}_{2}$.

It is required to study more precisely the temperature dependence of the susceptibility on an extremely pure specimen of chalcopyrite with more carefully controlled impurity concentrations.

Acknowledgment. - We would like to thank Professors Kambara and Gondaira for helpful discussions. Our sincere thanks are also due to Mr. Tamaki for measurements of the magnetic susceptibility.

\section{References}

[1] Boliaks, B. I. and Talnovskit, N. N., Zh. Tekh. Miz. 25 (1955) 402.

[2] Teranishi, T., J. Phys. Soc. Japan 16 (1961) 1881.

[3] Donnay, G., Corliss, L. M., Doninay, J. D. H., Ellott, N. and Hastings, R. M., Phys. Rev. 112 (1958) 1917.

[4] Goodman, C. H. L. and Douglas, R. W., Physica 20 (1954) 1107.

[5] Austin, I. G., Goodman, C. H. L. and Penglely, A. E., J. Electrochem. Soc. 103 (1956) 609.

[6] Teranishi, T., SAto, K. and Kondo, K., J. Phys. Soc. Japan $36(1974) 1618$.

[7] Kambara, T., J. Phys. Soc. Japan 36 (1974) 1625.

[8] Adaims, R., Braulieu, R., Vassiliadis, M. and Wold, A., Mater. Res. Bull. 7 (1972) 87.

[9] Selwood, P., Magnetochemistry (Interscience, New York) 1956, p. 78 .
[10] Shay, J. L., Tell, B., Kasper, H. M. and Shiavone, L. M., Phys. Rev. B 5 (1972) 5003.

[11] Sato, K, and Teranisiri, T., J. Phys. Soc. Japan 37 (1974) 415.

[12] Kambara, T., Suzuki, K. and Gondaira, K., to be published in J. Phys. Soc. Japan.

[13] Shocklex, W., Electrons and Holes in Semiconductors (van Nostrand, New York) 1950, p. 283.

[14] DigiushipPE, M., STEager, J., WOLd, A. and Kostiner, E., lnorg. Chem. 13 (1974) 1828.

[15] Wilson, A. H., The Theory of Metals (University Press, Cambridge) 1953, p. 151.

[16] Kachi, S., Takada, T., Bando, Y., Kosuge, K., OKINaka, H. and Nagasawa, K., Proc. Int. Conf. Ferrite, Kyoto (ed. by Hoshino, Iida and Sugimoto, Tokyo University Press) 1971, p. 563. 